\title{
ENTRE BABEL Y PENTECOSTÉS: JOSEPH DE MAISTRE EN LA DIVERSIDAD DE LAS LENGUAS
}

\author{
MARIANO SVERDLOFF \\ Facultad de Filosofía y Letras de la Universidad de Buenos Aires \\ Universidad Católica Argentina \\ CONICET \\ marianosverdloff@gmail.com \\ ORCID: 0000-0001-9365-9901
}

\section{RESUMEN}

Joseph de Maistre, figura fundacional de la antimodernidad, impugna constantemente los fenómenos de la pluralidad de las lenguas y de la traducción a partir de una teoría del lenguaje de fundamentos teológicos. Este rechazo convive, sin embargo, con el trato constante con otras lenguas antiguas y modernas y con la reflexión sobre los «intraducibles filosóficos», como diría B. Cassin. Paradójicamente, este crítico acérrimo del cosmopolitismo ilustrado configura en su escritura un original dispositivo de relación con las lenguas extranjeras, en donde se descentra tanto el universalismo de la clarté como la traducción etnocéntrica de las belles infidèles. A diferencia de otros contrarrevolucionarios, como el vizconde de Bonald o Lamennais, De Maistre presenta una escritura radicalmente fragmentada y plurilingüe, desde la cual piensa la relación entre lenguaje y verdad. Y, tal como demostraremos, esa violencia sobre el francés clásico está conectada estrechamente con otra violencia, la del acontecimiento revolucionario.

PALABRAS CLAVE: De Maistre, traducción, Babel, revolución, antimodernidad, aceleración.

\section{BETWEEN BABEL AND PENTECOST: JOSEPH DE MAISTRE AND THE DIVERSITY OF LANGUAGES}

\section{ABSTRACT}

Joseph de Maistre's theological theory of language has a strong bias against translation and plurilinguism. This position however coexists with constant references to ancient and modern languages, and reflections on what Barbara Cassin calls "philosophical untranslatables." Paradoxically, this staunch critic of enlightened cosmopolitanism offers an original reading of foreign languages; one of its main effects is to de-center the universalism of the clarté and the ethnocentric translation of the belles infidèles. Unlike other counterrevolutionaries, such as the Viscount de Bonald or Lamennais, De Maistre, a foundational figure of anti-modernity, presents a radically fragmented and multilingual textuality, that allows him to reflect on the relation between language and truth. As we intend to show in this paper, this violence on classical French is closely connected with revolutionary violence.

KEYWORDS: De Maistre, translation, Babel, revolution, anti-modernity, acceleration. 


\section{INTRODUCCIÓN}

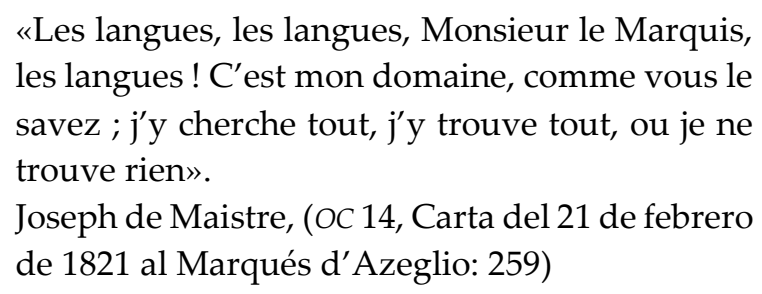

Las lecturas de los últimos años han cambiado la imagen que se tenía de Joseph de Maistre. Han sido revisadas las interpretaciones que, apoyándose en los momentos más ominosos de los textos del saboyano, lo consideraban solamente un precursor de los fascismos, tal como proponían Sternhell (2010), Berlin (2004[2002]) o Marcuse (2005[1936]). Sin descartar sus aspectos autoritarios, lecturas como las de Lebrun (2001) Armenteros (2011) o Pranchère (2004) inscribieron a De Maistre de lleno en el pensamiento histórico del siglo XIX. Por su parte Compagnon (2016) hizo de De Maistre una referencia fundamental de la «antimodernidad» baudelaireana. La mencionada Armenteros y Garrard (2006) exploraron las relaciones (a menudo paradójicas) con escritores como Rousseau y Voltaire, así como con otros autores contemporáneos, precisándose de ese modo el lugar del saboyano en la Contra-Ilustración. Un importante trabajo crítico ha sido llevado a cabo por la Revue des Études Maistriennes, animada entre otros por Darcel, quien publicó en 1993 una edición crítica de las Les soirées de Saint-Pétersbourg en Slatkine. También han contribuido a esta complejización de la imagen de la obra del conde el acceso digital a los archivos personales (que contienen manuscritos, cuadernos y correspondencia); aportes tales como el Dossier H (2005), compilado por Barthelet; o la notable edición de las CEuvres (2007) preparada por Glaudes, quien también ayudó de forma significativa a renovar la percepción crítica sobre la obra de De Maistre (Glaudes 1997, 2000). Uno de los efectos de esta complejización ha sido explorar, tal como se advierte en los textos de Cioran (2011[1977]) o del mencionado Compagnon, nuevas modulaciones de un aspecto central de la crítica maistriana: la figura de la paradoja. Quisiera pues, en este trabajo, analizar un aspecto todavía inexplorado, pero que convoca de algún modo al tropo de la paradoja, el de las tensiones entre la teoría y la práctica en el ámbito la traducción. Si bien han sido estudiadas las teorías de De Maistre sobre «l'origine du langage et ses diversités» (OC 7, Examen d'un écrit de J.-J. Rousseau: 554), fenómeno que es explicado por el saboyano en términos teológicos (Eco 1998, Froidefont 2010, Thurston 2005), ningún trabajo ha investigado hasta ahora el modo en que esas teorías se relacionan con las prácticas concretas de traducción y lectura de lenguas extranjeras.

El objetivo de estas páginas es pues acercarme al modo en que esta visión negativa del fenómeno de la traducción y de la diversidad lingüística se compagina, sin embargo, con el trato constante con las lenguas antiguas y modernas. Este negador de la traducción se comportaba como un «cosmopolita 
ilustrado», tal como permite apreciar un acercamiento de conjunto al archivo De Maistre. De este modo, este crítico acérrimo de la gramática de Port-Royal y de las teorías sensualistas sobre el lenguaje del abad de Condillac, configura en su escritura una original máquina de relación con las lenguas extranjeras antiguas y modernas, en donde se descentra tanto el valor estilístico de la clarté como la traducción etnocéntrica de las belles infidèles. A diferencia de otros contrarrevolucionarios, como el vizconde de Bonald o Lammenais, De Maistre exhibe en su escritura un intenso plurilingüismo. Tal como veremos, esa violencia sobre el francés clásico, en virtud de la cual ingresa lo extranjero, está conectada estrechamente con otra violencia, la del acontecimiento revolucionario.

\section{TEOLOGÍA Y COSMOPOLITISMO}

De Maistre asocia fuertemente a la multiplicidad lingüística con la corrupción. Tal como analizan los trabajos de Thurston (2005), Eco (1998) y Froidefont (2010), a partir de una lectura idiosincrática de fuentes teosóficas, masónicas y cristianas, De Maistre postula una teoría según la cual las lenguas históricas son el resultado de un proceso de degradación. El punto cero desde el cual se habría producido la caída de las lenguas humanas es una lengua original, sobre las que De Maistre da algunas pocas precisiones en sus textos (Thurston 2005), particularmente en el Essai sur Bacon (escrito en 1816 y de publicación póstuma en 1836). Esa lengua original excluiría la arbitrariedad y ofrecería una adecuación absoluta entre «idées innées» y «sons» (según la terminología del segundo entretien de las Soirées) y entre estos y la realidad. Sería esta la lengua más cercana al propio nombrar de Dios, que según el Génesis creó el universo a través del lenguaje. Para De Maistre, como explica Froidefont,

Le Verbe est Dieu, il est ce qui vivifie notre intelligence, tout comme le verbe vivifie la phrase. Dire les noms, et les dire en tant qu'il sont articulés à l'être, c'est, dans le vocabulaire maistrien, saisir par intuition l'essence des choses. (Froidefont 2010: 234)

Al romperse esa suerte de adaptación cratílica entre «nom»e «intuition» (es decir, entre y significante y significado) y entre «nom»y «essence des choses» (es decir, entre sentido y referencia), los conocimientos se harán confusos. En el planteo maistriano habría dos momentos fundamentales en esta caída: la expulsión del paraíso terrenal como resultado del pecado original (Gen. 3.1-24) y la construcción de la torre de Babel (Gen. 11.1-9). Thurston (2005) ha estudiado las explicaciones, bastante contradictorias, a partir de las cuales De Maistre intenta darle un fundamento histórico al relato bíblico de Babel.

Este monogenitismo lingüístico de base teológica conecta a la pluralidad de lenguas con la degradación. Si la lengua original era una y nació una sola vez, las lenguas degradadas serán múltiples y nacerán en diversos tiempos de la historia, 
lo cual supone distintos grados de lejanía en relación al origen. La historia de las lenguas se interpreta a partir de su corrupción: así como hay lenguas más alejadas de la verdad que otras, en la diacronía de cada lengua también se verifica este proceso de degradación, proporcional al alejamiento del origen:

Chaque langue, prise à part, répète les phénomènes spirituels qui eurent lieu dans l'origine et plus la langue est ancienne, plus ces phénomènes sont sensibles. (OC 4, Soirées: 97)

En el inicio de cada lengua se advertiría la mano del Creador, porque las lenguas no nacen espontáneamente por un acuerdo más o menos dificultosos entre los hombres en estado de naturaleza, sino que son instituidas de una vez por intervención divina:

Les langues ne peuvent être inventées ni par un seul homme qui n'aurait pu se faire obéir, ni par plusieurs hommes qui n'auraient pu s'accorder. (OC 7, Examen d'un écrit de J.-J. Rousseau: 554)

Esta perspectiva teológica supone un paralelismo entre los planos lingüístico y político; el hombre no puede inventar lenguas, así como tampoco puede inventar instituciones. De allí que el protestantismo o la revolución sean una confusio linguarum, una suerte de traducción de Babel al terreno político. Como se advierte, De Maistre discute con las filosofías políticas contractualistas y con las teorías del siglo XVIII sobre el origen del lenguaje, en particular con los planteos de Rousseau y con el sensualismo del abad de Condillac. A partir de este posicionamiento, De Maistre separa al «hombre natural» del origen del lenguaje: las lenguas de los «salvajes» no serían lenguas primitivas, sino más bien el resultado de un largo proceso de corrupción lingüística y moral. Así como en cada religión corrompida han de buscarse restos de la religión «verdadera», en las lenguas de los «salvajes» pueden advertirse trazas de la lengua original.

Este planteo supone que la tarea del traductor y del lector de lenguas antiguas y modernas es relevar en cada lengua histórica las huellas de la lengua original. De allí que De Maistre sugiera la posibilidad de un comparatismo de base teológica, en virtud del cual podrían deducirse los parecidos entre las lenguas que, se supone, remitirían a la lengua original. ${ }^{1}$ El ejercicio de traducción y de comparación de lenguas se concibe como un remontar hacia arriba la corriente de la degradación. La traducción no sirve para «ilustrar» la lengua francesa, tal como planteaban los discursos sobre la traducción del siglo XVI; o para traer tal o cual obra del genio de otra lengua al genio de la lengua francesa, como se decía en el siglo XVIII. La operación de traducción y de lectura de lenguas extranjeras supone, más bien aproximarse a la verdad. Y esta verdad se define en términos de una oralidad divina, es decir apelando a la poderosa tradición del

\footnotetext{
${ }^{1}$ «Je pourrais vous montrer dans l'un de ces volumes manuscrits que vous voyez sur ma table, plusieurs pages chargées de mes pieds de mouche, et que j'ai intitulées Parallélismes de la langue grecque et de la française» (OC 4: Soirées, 96).
} 
logocentrismo occidental (Derrida 1967: 11 y ss.). De Maistre recupera en términos teológicos el extendido tópico de la primacía de la oralidad sobre la escritura:

Les langues ont commencé ; mais la parole jamais, et pas même avec l'homme. L'un a nécessairement précédé l'autre ; car la parole n'est possible que par le VERBE. (OC 4: Soirées, 99)

Si el nombrar de los hombres deriva del nombrar divino de Dios en el Génesis, este poder se conservará sobre todo en la palabra hablada. Como bien ha mostrado Thurston $(2001,2010)$, esta perspectiva logocéntrica supone un fuerte rechazo al mundo del impreso, que De Maistre asocia con la Ilustración. Y también con el protestantismo, en la medida en que la imprenta permite la circulación de textos fuera de ámbitos controlados por la Iglesia, y por tanto es el dispositivo ideal para la lectura de la Biblia en términos de la sola scriptura que defendían los reformadores. De Maistre propone pues una estructura de doble reenvío: de la lengua moderna (siempre corrompida) a la lengua original; y de la escritura a la oralidad, cuya forma más alta es la oralidad divina, es decir la Palabra. En tanto suplemento (Derrida 1967: 17 y ss.), la palabra escrita, sobre todo la de una lengua moderna como el francés del siglo XVIII, sería apenas un residuo, un fragmento degradado a partir del cual será posible remontarse al origen divino.

A partir de esta visión teológica, De Maistre piensa la inscripción de las lenguas en la historia. Uno de los efectos de esta concepción decadentista es una apertura historicista a la diversidad de las lenguas, que descentra el universalismo ilustrado. Todas las lenguas distan de la lengua original, en mayor proporción las modernas que las antiguas, pero cada una lo hace a su manera. De allí que no todo pueda ser dicho en cualquier lengua (y mucho menos la Biblia, según se advierte en las críticas a las traducciones hechas por la Sociedad Bíblica y Port-Royal ${ }^{2}$ ). Y si todas las lenguas estás más o menos degradadas, habrá diversos genios inconmensurables unos con otros, pero ninguna de estas lenguas podrá manifestar una verdad universal, al modo en que proponía la gramática de Port-Royal o sus lectores del siglo XVIII. Esta inconmensurabilidad está en la base de la defensa anti-universalista del prejuicio (OC 12, Carta al rey VíctorEmanuel del 6 [18] de julio de 1812,62) y en la creencia en la intraductibilidad de los conceptos filosóficos. ${ }^{3}$ En su momento más puro, es decir en sus orígenes, cada lengua expresa una particular visión de mundo no universalizable. Y

2 «Si l'on établissait une société pour acheter et brûler toutes les traductions de la Bible en langues vulgaires, je serais violemment tenté d'en être» (OC 13, Carta al príncipe Korlowski del 2 [14] de febrero de 1816: 253).

${ }^{3}$ «La constitution de 1795, tout comme ses aînées, est faite pour l'homme. Or, il n'y a point d'homme dans le monde. J'ai vu, dans ma vie, des Français, des Italiens, des Russes, etc., je sais même, grâce à Montesquieu, qu'on peut être Persan : mais quant à l'homme, je déclare ne l'avoir rencontré de ma vie ; s'il existe, c'est bien à mon insu» (OC 1, Considérations sur la France: 74$)$. 
asimismo en sus orígenes, cada lengua excluye lo arbitrario, en el sentido de que responde a una suerte de ley inmanente, detrás de la cual se encontraría, por supuesto, la mano de la providencia: «Chaque langue a son génie, et ce génie est UN, de manière qu'l exclut toute idée de composition, de formation arbitraire et de convention antérieure». (OC 4, Soirées: 91).

Este genio de cada lengua se manifestaría, sobre todo, entonces, en la infancia de los pueblos, es decir en un tiempo cercano al de la instauración de la lengua por medio de la inspiración divina. No se trata de la lengua de un «hombre natural», como el que imaginaban las teorías del siglo XVIII, sino de una lengua tutelada por Dios, quien garantiza la adecuación entre pensamiento y realidad: «chaque mot est vrai, c'est-à-dire qu'il n'est point imaginé arbitrairement « (OC 4, Soirées: 101). A partir de esta visión histórica que divide la historia de las lenguas en dos épocas, De Maistre establece una nítida frontera en el modo en que las lenguas se relacionan con el extranjero. Por un lado, los «peuples enfants» manifiestan un «talent onomaturge» (OC 4, Soirées: 103), es decir crean orgánicamente nombres en su lengua; y si «se nutren» de otras lenguas, «las trituran, las digieren» (OC 4, Soirées: 93) de forma natural, sin alterar el genio primigenio de la lengua propia. Por el otro, los pueblos ya corrompidos por la filosofía y la abstracción filosófica se arrojan hacia un cosmopolitismo intelectualista en el cual los vocablos extranjeros son adoptados violando el genio particular de cada lengua. De Maistre reinterpreta a su modo la idealización dieciochesca de las épocas cercanas a la naturaleza, particularmente del pasado griego, idealización que nutriría, por ejemplo, las especulaciones estéticas de Winckelmann o la oposición schilleriana entre naive y sentimentalische Dichtung. Coherentemente, tanto en las Soirées como en su larga discusión contra el segundo discurso de Rousseau, De Maistre postula que los poemas homéricos son una prueba de la influencia divina sobre los orígenes del griego: una lengua tan sutil y compleja no podría haber surgido espontáneamente en una época de semejante grado de barbarie (OC 7, Examen d'un écrit de J.-J. Rousseau: 545; OC 4, Soirées: 98). Y en la misma línea, en el segundo entretien de las Soirées el Conde (alter ego de De Maistre) se entrega a una larga serie de fantasiosos ejercicios etimológicos, a los efectos de probar la diferencia que existe entre la organicidad de las lenguas en sus orígenes y el artificio (es decir la improductividad) de las lenguas de «les époques de civilisation et de science» (OC 4, Soirées: 103). En términos estrictamente filológicos, estos ejercicios carecen de todo interés (Eco 1998). Pero nos permiten aproximarnos a una de las obsesiones del pensamiento maistriano, el vínculo del lenguaje con la historia y la política. La preocupación por este vínculo se advierte en la identificación entre lengua y nación (OC 14, Carta del 15 de noviembre de 1817 a Bonald: 114) o entre lengua y soberanía (OC 14, Carta al Marqués de Azeglio, 21 de febrero de 1821: 258). El lenguaje, para De Maistre, es una suerte de termómetro moral de los pueblos. De allí que uno de los tópicos más recurridos de sus textos contrarrevolucionarios sea la crítica del lenguaje, en una dirección similar a la de otros críticos del proceso iniciado 
en 1789, tales como Jean-François de La Harpe, quien publicó en $1797 \mathrm{Du}$ fanatisme dans la langue révolutionnaire (Thurston 2001). De hecho, tal como veremos, De Maistre, se explayará largamente sobre la relación entre traducción y violencia revolucionaria. No deja de ser irónico que esta aguda conciencia finalmente tan moderna - en torno a la historicidad de la traducción se apoye en la tradición teológica de Babel (una tradición que hunde sus raíces en la antigüedad y llega hasta bien entrado el siglo XVII, para comenzar a secularizarse paulatinamente). ${ }^{4}$ Un verdadero anacronismo, si tenemos en cuenta que De Maistre escribe entre el siglo XVIII, es decir el siglo de las explicaciones naturalistas sobre el origen del lenguaje, y el siglo XIX, es decir el siglo de la filología científica.

Ahora bien: esta repulsa teológica de la traducción, que supone la nostalgia por una lengua original, debe ser confrontada, sin embargo, con las prácticas de traducción concretas. Y estas prácticas convergen con el plurilingüismo de la «Ilustración cosmopolita» (AA.VV. 2011). Existe, pues una notable distancia entre los postulados teológicos maistrianos y la materialidad de sus textos. Esto no resulta sorprendente, si pensamos que De Maistre no era un pensador sistemático y que cada texto debe ser contextualizado, antes que en una filosofía coherente, en el horizonte de una serie de discusiones coyunturales, altamente polarizadas, cada una de las cuales supone distintos interlocutores y públicos (por lo demás De Maistre, desconfiado de la escritura, era bastante renuente a pensar sus escritos en términos de la congruencia de una «obra»). No es posible, pues, pensar las prácticas de traducción a partir de las ardientes defensas del monolingüismo que encontramos en textos como Du Pape (1819). Lo cierto es que este negador de Babel nunca cesó de traducir y de reflexionar sobre el fenómeno de la traducción, es decir, de diseminar la diferencia entre las lenguas (Cassin 2016: 64-70). Hacer una reseña de los contactos de De Maistre con el universo de la traducción equivaldría a escribir su biografía. Recordemos solamente que el saboyano recibió una formación retórica clásica, que implicaba una práctica cotidiana de traducción primero del latín y después del griego. Asimismo, De Maistre creció en un entorno plurilingüe, dado que Chambéry pertenecía a la casa de Saboya, que formaba parte del reino de Cerdeña, cuyo trono estaba en Turín. A lo cual debemos sumar las redes transnacionales e interlingüísticas que suponen la masonería, la política, la diplomacia, los viajes y los exilios. De Maistre vivió en Lausanne, Turín, San Petersburgo, visitó Roma, Florencia, Viena. El catálogo de la biblioteca en varias lenguas antiguas y modernas y los cuadernos de anotaciones conservados en el archivo de la familia De Maistre son el testimonio de esta práctica cosmopolita. ${ }^{5}$ Un plurilingüismo que ingresará en

\footnotetext{
${ }^{4}$ Sobre la tradición de Babel $c f r$. las entradas de Luhtala, Amsler, Carvalhão Buescu, Maat, Droixhe, Dutz y Kaczmarek en Auroux, Koerner, Niederehe y Versteegh (2000-2).

${ }^{5}$ Es particularmente interesante consultar el catálogo de la biblioteca de De Maistre, acessible en los archivos departamentales de Saboya bajo la signatura 2J 31 (https://francearchives.fr/ es/facomponent/0195caa3186719081a7a617d98a161de73b97bbf).
} 
el propio cuerpo de los textos, tal como se advierte, por ejemplo, en las densas referencias de L'éclaircissement sur les sacrifices (1821) - las cuales por lo demás hacen tan difícil traducir este texto a otras lenguas. De Maistre leía en inglés, italiano, español, portugués y (con dificultad) en alemán (introducción de Lebrun en AA.VV. 2001: 4), tenía rudimentos de ruso, y mostraba interés por los estudios de hebreo, sánscrito, chino y japonés, por más que nunca llegó a aprender esas lenguas. En varios momentos de la correspondencia maistriana la curiosidad suspende a la decodificación teológica y el desprecio logocéntrico por la palabra escrita, tal como se advierte cuando discute aspectos del ruso (OC 13, Carta al conde de Vallaise del 21 de marzo [2 de abril] de 1816: 306), de la lengua china (OC 14, Carta a M. Dumont del 27 de febrero de 1818: 127) o la posibilidad de una «pasigraphie» que ayudara a transliterar las lenguas orientales (OC 14, Carta a M. Dumont del 3 de enero de 1818: 120).

Todos estos flujos transnacionales se compaginan con una mirada de soslayo y desconfiada sobre el «francés de París», que para De Maistre equivale a la enciclopedia, a los philosophes y a los derechos del hombre (OC 10, Carta al caballero de Rossi del 9 [21] de marzo de 1807: 325). De Maistre entiende al francés del siglo XVIII como una poderosa fuerza que puede describirse en términos de una retórica de lo sublime, pero no lo considera un ámbito en el cual pueda expresarse la verdad. El saboyano articula desde la periferia de Chambéry (y luego desde el exilio) una mirada sobre el francés con muchos más reparos que la que encontramos en un Rivarol o un Diderot. A su modo, De Maistre pone en cuestión el universalismo del francés, así como el etnocentrismo lingüístico que supone. Tal como veremos, este posicionamiento, al entrecruzarse con la violencia revolucionaria, arrojará resultados sumamente paradójicos en el espacio de la traducción.

\section{VIOLENCIA REVOLUCIONARIA Y UNIVERSALIZACIÓN PROVIDENCIAL}

Un fragmento del segundo entretien de las Soirées revela la conexión que según De Maistre existe entre traducción y revolución, conexión que se apoya a su vez en el vínculo entre historia y providencia:

Je n'éprouve nulle peine à me résigner ; je vous l'avouerai même, si j'étais isolé, et si les coups qui m'ont atteint n'avaient blessé que moi, je ne regarderais tout ce qui s'est passé dans le monde que comme un grand et magnifique spectacle qui me livrerait tout entier à l'admiration ; mais que le billet d'entrée m'a coûté cher!.... Cependant je ne murmure point contre la puissance adorable qui a si fort rétréci mon appartement. Voyez comme elle commence déjà à m'indemniser, puisque je suis ici, puisqu'elle m'a donné si libéralement des amis tels que vous. Il faut d'ailleurs savoir sortir de soi-même et s'élever assez haut pour voir le monde, au lieu de ne voir qu'un point. Je ne songe jamais sans admiration à cette trombe politique qui est venue arracher de leurs places des milliers d'hommes destinés à ne jamais se connaître, pour les faire tournoyer ensemble comme la poussière des champs. Nous sommes trois ici, par exemple, qui étions nés pour ne jamais nous 
connaître ; cependant nous sommes réunis, nous conversons ; et quoique nos berceaux aient été si éloignés, peut-être que nos tombes se toucheront.

Si le mélange des hommes est remarquable, la communication des langues ne l'est pas moins. Je parcourais un jour dans la bibliothèque de l'Académie des sciences de cette ville, le Museum sinicum de Bayer, livre qui est devenu, je crois, assez rare, et qui appartient plus particulièrement à la Russie, puisque l'auteur, fixé dans cette capitale, y fit imprimer son livre, il y a près de quatre-vingts ans. Je fus frappé d'une réflexion de cet écrivain savant et pieux. "On ne voit point encore, dit-il, à quoi servent nos travaux sur les langues; mais bientôt on s'en apercevra. Ce n'est pas sans un grand dessein de la Providence que les langues absolument ignorées en Europe, il y a deux siècles, ont été mises de nos jours à la portée de tout le monde. Il est permis déjà de soupçonner ce dessein ; et c'est un devoir sacré pour nous d'y concourir de toutes nos forces." Que dirait Bayer, s'il vivait de nos jours ? La marche de la Providence lui paraîtrait bien accélérée. Réfléchissons d'abord sur la langue universelle. Jamais ce titre n'a mieux convenu à la langue française ; et ce qu'il y a d'étrange, c'est que sa puissance semble augmenter avec sa stérilité. Ses beaux jours sont passés : cependant tout le monde l'entend, tout le monde la parle ; et je ne crois pas même qu'il y ait de ville en Europe qui ne renferme quelques hommes en état de l'écrire purement. La juste et honorable confiance accordée en Angleterre au clergé de France exilé, a permis à la langue française d'y jeter de profondes racines : c'est une seconde conquête peut-être, qui n'a point fait de bruit, car Dieu n'en fait point, mais qui peut avoir des suites plus heureuses que la première. Singulière destinée de ces deux grands peuples, qui ne peuvent cesser de se chercher et de se haïr! Dieu les a placés en regard comme deux aimants prodigieux qui s'attirent par un côté et se fuient par l'autre, car ils sont à la fois ennemis et parents. Cette même Angleterre a porté nos langues en Asie, elle a fait traduire Newton dans la langue de Mahomet, et les jeunes Anglais soutiennent des thèses à Calcutta, en arabe, en persan et en bengali. De son côté, la France qui ne se doutait pas, il y a trente ans, qu'il y eût plus d'une langue vivante en Europe, les a toutes apprises, tandis qu'elle forçait les nations d'apprendre la sienne. Ajoutez que les plus longs voyages ont cessé d'effrayer l'imagination; que tous les grands navigateurs sont européens ; que l'Orient entier cède manifestement à l'ascendant européen; que le Croissant, pressé sur ses deux points, à Constantinople et à Delhi, doit nécessairement éclater par le milieu ; que les événements ont donné à l'Angleterre quinze cents lieues de frontières avec le Thibet et la Chine, et vous aurez une idée de ce qui se prépare.

L'homme, dans son ignorance, se trompe souvent sur les fins et les moyens, sur ses forces et sur la résistance, sur les instruments et sur les obstacles. Tantôt il veut couper un chêne avec un canif, et tantôt il lance une bombe pour briser un roseau ; mais la Providence ne tâtonne jamais, et ce n'est pas en vain qu'elle agite le monde. Tout annonce que nous marchons vers une grande unité que nous devons saluer de loin, pour me servir d'une tournure religieuse. Nous sommes douloureusement et bien justement broyés ; mais si de misérables yeux tels que les miens sont dignes d'entrevoir les secrets divins, nous ne sommes broyés que pour être mêlés. (OC 4, Soirées: 124-7)

La revolución, a la que se define como una «trombe», es equiparable a un espectáculo natural de características sublimes, en la medida en que amenaza la integridad del sujeto que lo contempla. Pero este espectáculo obliga a salir de sí mismo, a romper con los ámbitos de pertenencia naturales y a buscar nuevos interlocutores en el contexto de una sociabilidad cosmopolita. La revolución 
obliga, por tanto, a la traducción. Impulso que iría en la misma dirección que otro movimiento que surca el siglo XVIII, el de la aceleración de la «communication des langues». En este pasaje, como se advierte, el cataclismo revolucionario y la mundialización de las lenguas son presentados como fenómenos simultáneos, coordinados por la mano oculta de la Providencia. Compaginando también pluralidad de lenguas con aceleración revolucionaria, en el Étude sur la souveraineté (escrito en 1794, de publicación póstuma en 1870) De Maistre inscribía a la confusión babélica en el corazón del momento revolucionario. El esfuerzo de los hombres por auto-organizar la vida social mediante las leyes racionales explícitamente formuladas de una constitución escrita produciría una confusión comparable a la de Babel:

La tour de Babel est l'image naïve d'une foule d'hommes qui s'assemblent pour créer une constitution. "Venez, se disent les ENFANTS DES HOMMES; bâtissons-nous une ville et une tour dont le sommet s'élève jusqu'au ciel, pour rendre notre nom célèbre, avant que nous soyons dispersés."

Mais l'ouvrage s'appelle Babel, c'est-à-dire confusion; chacun parle sa langue ; personne ne s'entend, et la dispersion est inévitable.

Il n'y a jamais eu, il n'y aura jamais, il ne peut y avoir de nation constituée à priori. (OC 1, Étude sur la souveraineté: $368-9$ )

La división de las lenguas está íntimamente ligada, pues, con el acontecimiento revolucionario. ${ }^{6}$ Claro que, supone De Maistre, en breve sin embargo habrá una reintegración. De Maistre interpreta a la revolución, como se sabe, a partir la loi de la réversibilité, en virtud de la cual el mal ha de trocarse en bien. Y supone que la lengua, cuyas vicisitudes también expresan a la Providencia que actúa detrás de la historia, acompaña esta reintegración del mal en el bien, es decir, de la multiplicidad en la unidad. Como ha sido advertido por la crítica, los dos momentos fundamentales de la lengua en términos de la visión teológica de De Maistre son Babel y Pentecostés:

Après avoir examiné l'homme, examinons ce qu'il y a de plus merveilleux en lui, la parole ; nous trouverons encore le même mystère, c'est-à-dire, division inexplicable et tendance vers une certaine unité tout aussi inexplicable. Les deux plus grandes époques du monde spirituel sont sans doute celle de Babel, où les langues se divisèrent, et celle de la Pentecôte où elles firent un merveilleux effort pour se réunir. (OC 5, Soirées: 168-9)

Según el libro de los Hechos del Nuevo Testamento durante la festividad judía de Pentecostés, el Espíritu Santo descendió en Jerusalén sobre los apóstoles de Cristo. El Espíritu Santo se manifestó en forma de «lenguas como fuego»

\footnotetext{
${ }^{6}$ Por lo demás, no deja de ser irónico que un revolucionario como Bertrand Barère, apodado «el Anacreonte de la guillotina», utilizara el imaginario de Babel para describir el estado de la lengua durante el Antiguo Régimen y la necesidad de una intervención homogeneizadora por parte del estado (Balibar y Laporte 1974: 94).
} 


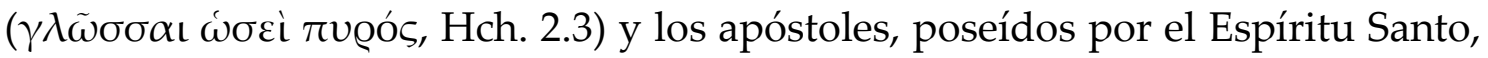

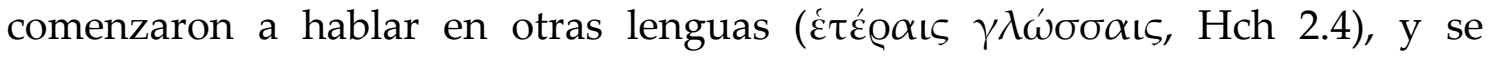
dirigieron a los otros judíos que habían concurrido desde diversas regiones a la festividad del Pentecostés, quienes escucharon cada uno en su propia lengua

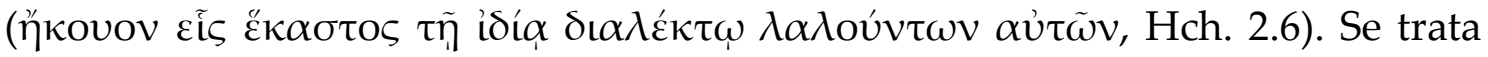
pues de una imagen de unión a la vez espiritual y lingüística (y también política, en la medida en que el descenso del Espíritu Santo en Jerusalén durante Pentecostés es una escena fundamental en la narrativa de la expansión de la Iglesia primitiva). Para De Maistre estas dos «grandes époques du monde spirituel», la de Babel y la de Pentecostés, no son solamente acontecimientos de la historia sagrada que ocurrieron factualmente, sino que también le sirven como categorías interpretativas del siglo XVIII y de la época revolucionaria. ${ }^{7} \mathrm{La}$ aceleración de la "puissance adorable» es tanto un momento de división de los hombres y de sus lenguas como un presagio de su próxima reunificación. La época parece estar habitada por las fuerzas contrapuestas de la división y de la unión espiritual. Y la próxima llegada del nuevo Pentecostés, que según parece De Maistre identificaba con la «Tercera Época» o «Época del Espíritu Santo» del místico hereje Joaquín de Fiore (Lubac 1989: 287-306), supone una intensificación de los intercambios traductivos. Paradójicamente, el instrumento que permite la unificación de las lenguas es la traducción, a la que De Maistre mira con tanta desconfianza. De hecho, ejecutar el mandato providencial de unificación espiritual supone traducir y explicar una lengua por medio de otra, según se deduce del prefacio del Museum sinicum, gramática china editada en 1730 por el erudito protestante prusiano Theophilus Siegfried Bayer en la muy cosmopolita y recientemente fundada San Petersburgo. En el pasaje de las Soirées que he citado más arriba, De Maistre destaca esta interpretación providencialista de la traducción enunciada por Bayer en el prefacio a su gramática y la relee en términos de su propia idea de la relación entre traducción y aceleración histórica. Detengámonos pues en este punto: la cercanía de la lengua universal se cimenta en la aceleración de las operaciones de traducción. De Maistre comprende perfectamente que en el siglo XVIII ha comenzado ese proceso de traducción generalizado que estará en la base, por ejemplo, de la noción de Weltliteratur de Goethe:

La Weltliteratur est bien plutôt l'âge de la traduction généralisée, dans lequel toutes les langues apprennent, sur leur mode propre à être des langues-de-traduction et à vivre l'expérience de l'inter-traduction

\footnotetext{
${ }^{7}$ Nótese por lo demás que, como ha notado Cassin (2016: 198-9) la propia escena de unificación lingüística de Pentecostés supone el fenómeno de la traducción: no sucede que cada uno de los judíos entiende la lengua del Espíritu Santo, sino que esta lengua sagrada se autotraduce a las diferentes lenguas de cada hablante para poder ser comprendida.
} 
dice Berman en L'épreuve de l'étranger (2011: 94). Claro que a diferencia de la Bildung cosmopolita goetheana, el resultado final de este movimiento de traducción generalizada debe ser la unificación bajo un imperium concebido en términos teológico-políticos, y por añadidura lingüísticos, tal como se define en Du pape (1819). Esta aceleración supone no solamente la traducción de las lenguas europeas, sino también la traducción de las lenguas orientales bajo la hegemonía del inglés y del francés. El colonialismo lingüístico, un aspecto que por lo demás está presente en diversos elogios de la lengua francesa del siglo XVIII, tal como el de Rivarol, al que volveremos más abajo, se integra al plan providencial.

Ahora bien: la misma aceleración que produce la unificación, y que hace del francés una «langue universelle», muele y mezcla a los hombres. No sería forzado suponer que también muele y mezcla a las lenguas, y que esta universalización no es un proceso pacífico desde el punto de vista de las lenguas, en la medida en que las aleja absolutamente esa unidad idealizada, descripta en términos de un organicismo espiritualista, que De Maistre percibe en las lenguas que están más cercanas al origen divino. Las lenguas del final de Babel pueden presagiar Pentecostés, pero están ellas mismas degradadas, siendo su caso más extremo las retóricas revolucionarias. De hecho, el principal instrumento de esta universalización, el idioma francés de fines del siglo XVIII y principios del XIX, participa de este carácter paradójico: «sa puissance semble augmenter avec sa stérilité». Una potencia que, por lo demás, se describe en términos de una violenta expansión militar:

La moindre opinion que vous lancez sur l'Europe est un bélier poussé par trente millions d'hommes. Toujours affamés de succès et d'influence, on dirait que vous ne vivez que pour contenter ce besoin ; et comme une nation ne peut avoir reçu une destination séparée du moyen de l'accomplir, vous avez reçu ce moyen dans votre langue, par laquelle vous régnez bien plus que par vos armes, quoiqu'elles aient ébranlé l'univers. (OC 4, Soirées: 378 )

Nótese que De Maistre retoma tópico del poder geopolítico del francés, que encontramos arquetípicamente en el De l'universalité de la langue française (1784) de Antoine de Rivarol, discurso escrito como respuesta a un concurso llamado en 1783 por la Academia de Berlín cuyo tema era la causa de la hegemonía del francés, y si esta duraría. Pero este poder ya no se asienta en una razón universal que sería expresada por la clarté, tal como pretendía Rivarol. ${ }^{8}$ Porque para De Maistre, el lógos está en la palabra divina. El francés puede ser un instrumento, todo lo eficaz que se quiera, pero no será la lengua de la unificación de Pentecostés. El francés universaliza a la vez la unidad (unifica el mundo obedeciendo a los dictados de la voluntad divina), pero también universaliza la división (la lengua universalizada es la de los filósofos del siglo XVIII, o peor aún,

\footnotetext{
8 «la syntaxe française est incorruptible. C'est de là que résulte cette admirable clarté, base éternelle de notre langue. CE QUI N'EST PAS CLAIR N'EST PAS FRANÇAIS ; ce qui n'est pas clair est encore anglais, italien, grec ou latin» (Rivarol 1797[1784]: 32).
} 
la lengua de los revolucionarios). Naturalmente, explica De Maistre, la Providencia se encargará de poner a su debido tiempo la división al servicio de la unidad, es decir el mal al servicio del bien. De alguna forma, De Maistre, descentra la autoconfianza que los ilustrados, deudores de Port-Royal, tenían en el francés como lengua de la razón. Recordemos solamente, para ilustrar este punto, un pasaje de la «Lettre sur les Sourds \& les Muets» (1751) de Diderot, en el cual se argumenta que el orden natural del pensamiento, traicionado por las «lenguas de inversión» (es decir el latín y el griego, que permiten una gran movilidad sintáctica), en realidad se verifica en el francés:

Nous disons les choses en françois comme l'esprit est forcé de les considérer en quelque langue qu'on écrive. Cicéron a pour ainsi dire suivi la syntaxe françoise, avant que d'obéir à la syntaxe latine. (Diderot 1772[1751]: 68)

Esta confianza en el orden razonable del francés no tiene sentido para De Maistre, por varios motivos. El primero de ellos es que habría dos candidatos a expresar la verdad de forma más fiel que el francés: el hebreo del Antiguo Testamento, que, sugiere De Maistre en varios pasajes, es el idioma conocido más cercano al origen del lenguaje, y por tanto a la palabra divina; o bien el latín, el «signe européen» (OC 2, Du pape: 162), que, en tanto lengua de la Iglesia, cuenta con las necesarias credenciales teológico-políticas. Un segundo motivo es la desconfianza de De Maistre en relación a la escritura: el valor estilístico de la clarté nada tiene que ver con una oralidad que De Maistre asocia con la Palabra divina. Y un tercer motivo es que para De Maistre, en virtud de su excesiva sofisticación intelectual, el francés habría entrado en una etapa de hipercodificación "decadente", perdiéndose la creativa espontaneidad del origen de la lengua. El francés se ha convertido en el vehículo de una razón abstracta que pretende sustituir a la verdad de la revelación, pero la cercanía a la verdad de las lenguas no puede medirse en términos de su «razonabilidad», sino más bien en términos de su cercanía al origen divino. Como hemos visto más arriba, esta crítica a la presunción de universalidad del francés se compagina con cierta apertura a la pluralidad lingüística. Cada lengua es una visión de mundo particular, piensa De Maistre, en términos que la crítica ha aproximado a Herder. De allí la insistencia en la intraductibilidad de la filosofía:

Ces ouvrages doivent perdre aux traductions, parce que ce qu'on appelle le trait, et qui est essentiel dans la pensée, n'est pas le même dans les diverses langues. (OC 14, Carta del 2 de diciembre de 1817 a Bonald: 321)

dice por ejemplo De Maistre a propósito de una traducción reciente de Pascal al alemán.

Para De Maistre, entonces, el francés, en tanto lengua universal, es una lengua que no dice la verdad: es «universal» en la medida en que sirve para la unificación del mundo, a causa de su eficacia, pero no es «universal» en el sentido 
de que su sintaxis, su literatura, o el modo de pensar que a ellas subyace, sean «verdaderas». La lengua francesa del siglo XVIII, tiene una suerte de estatus intermedio: participa del movimiento de restauración de la palabra divina, pero el origen o la culminación de este movimiento le son exteriores (no podría ser de otro modo dado que la lengua de los philosophes niega, precisamente, a la Providencia). La verdad se expresará, según parece, en la lengua que vendrá en Pentecostés. No queda claro en la argumentación maistriana la relación, en términos teológicos, entre esa lengua y la lengua original que se describe en el Essai sur Bacon. Como sea, todo el imaginario de la clarté, tal como era definido por Diderot o Rivarol, estalla. La lengua francesa no es más la sede de la verdad: De Maistre se une así a esa tradición subterránea que, de forma contrapuntística, impugna a los elogios del francés, una tradición que Philippe ha analizado en Le français, dernière des langues (2010). En todo caso, la lengua francesa debe reenviar a otra instancia en la que sí está la verdad: la «Parole». Y aunque no se puede llegar directamente a la Palabra, si se puede llegar a sus intermediarios: las Escrituras, o la filosofía que la transmiten, que puede estar en otras lenguas: griego, latín, pero también sánscrito, ocasionalmente alguna lengua moderna. La lengua francesa, entonces, deviene una lengua de traducción y una lengua de reflexión sobre la traducción: a ella traduce De Maistre textos de otras lenguas y en ella reflexiona sobre la distancia entre cada lengua histórica y la verdad de la lengua original. Se trata de un movimiento hacia el pasado, es decir hacia lenguas anteriores, y hacia el origen de la propia lengua. Y de un movimiento hacia el futuro, porque esa aceleración de la operación de traducción apunta a una conciliación inminente. En los textos de De Maistre, el francés se convierte en una superficie de reflexión sobre la distancia o cercanía que cada lengua tiene en relación a la Palabra. No es un resultado sino un proceso dinámico, consagrado a la traducción. Lo cual implicará una destrucción de la clarté, a manos de unos textos que estarán también, como los hombres de la revolución, broyés y mêlés. Desde la perspectiva de este planteo teológico, el francés se mundializa por un mandato providencial, pero al hacerlo, recibe también fragmentos «molidos y mezclados» de lenguas extranjeras.

\section{DESTRUCCIÓN DE LA CLARTÉ Y VERDAD}

La traducción durante el siglo XVIII se define por la discusión en torno a la posibilidad de mediación entre los «genios» de la lengua propia y la extranjera, tal como se advierte en la entrada «Traduction» escrita por Marmontel para el

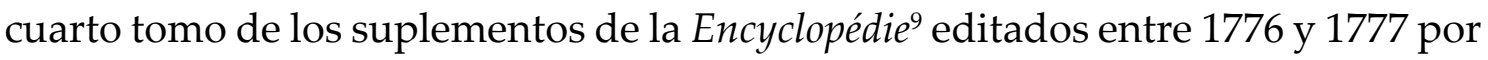

\footnotetext{
${ }^{9}$ «Les opinions ne s'accordent pas sur l'espece de tâche que s'impose le traducteur, ni sur l'espece de mérite que doit avoir la traduction. Les uns pensent que c'est une folie que de vouloir assimiler deux langues dont le génie est différent; que le devoir du traducteur est de se mettre à la place de son auteur autant qu'il est possible, de se remplir de son esprit, \& de le faire s'exprimer
} 
Panckoucke. Se trata de un período sumamente complejo, animado de tensiones entre el etnocentrismo y el interés por lo extranjero, al que solo una visión simplista podría interpretar a partir del conocido mote de «belles infidèles», que se aplicó a las traducciones de Perrot d'Ablancourt (Chevrel, Cointre y Tran Gervat 2014: 1282). Le sigue el momento romántico, en el cual, tal como se advierte en el elogio de Madame de Staël en De l'Allemagne (1813) a la traducción de Homero hecha por Voss, se pone en primer plano el respeto por la literalidad. Chateaubriand, en su traducción del Paradise Lost de Milton (Le paradis perdu, 1836), será uno de los exponentes más claros de esta apertura hacia la letra extranjera. Chevrel, D'hulst y Lombez, en la Histoire des traductions en langue française llaman al siglo XIX «siglo de la comparación» (2012: 31-50), en virtud de la creciente apertura de la lengua francesa hacia las lenguas y literaturas extranjeras. Todo este paisaje se define por la pregunta en cuanto a cómo armonizar dos lenguas, es decir, la pregunta por la relación entre lo propio y lo extranjero. De Maistre, a partir de su perspectiva teológica, ciertamente anacrónica a fines del siglo XVIII, piensa la traducción y la multiplicidad de las lenguas en términos de la relación con la verdad, es decir con la Palabra, y pone hasta cierto punto entre paréntesis el debate en torno a la relación entre los «genios» del francés y las lenguas extranjeras. Detrás de la relación entre dos lenguas históricas debe buscarse una tercera lengua, la del origen divino. Desde esta perspectiva, el traductor debe acercarse a los textos extranjeros rastreando en ellos las huellas de la lengua original anterior a la degradación. Para de De Maistre en las lenguas, como en el universo todo, se traman el orden y el desorden. Recordemos un conocido pasaje de las Soirées, un verdadero locus classicus de los estudios baudelaireanos, en el cual la crítica, desde Benjamin (1991: 477, J 86,2) hasta Labarthe (2015: 363), ha encontrado una prefiguración de la noción de «correspondencia» de Les Fleurs du mal:

Ils parlent de désordre dans l'univers; mais qu'est-ce que le désordre ? c'est une dérogation à l'ordre apparemment; donc ou ne peut objecter le désordre sans confesser un ordre antérieur, et par conséquent l'intelligence. On peut se former une idée parfaitement juste de l'univers en le voyant sous l'aspect d'un vaste cabinet d'histoire naturelle ébranlé par un tremblement de terre. La porte est ouverte et brisée ; il n'y a plus de fenêtres ; des armoires entières sont tombées; $\mathrm{d}$ 'autres pendent encore à des fiches prêtes à se détacher. Des coquillages ont roulé dans la salle des minéraux, et le nid d'un colibri repose sur la tête d'un crocodile. Cependant quel insensé pourrait douter de l'intention primitive, ou croire que l'édifice fut construit dans cet état ? Toutes les grandes masses sont ensemble : dans le moindre éclat d'une vitre on la voit tout entière ; le vide d'une layette la replace : l'ordre est aussi visible que le désordre ; et l'œil, en se promenant dans ce vaste temple de la nature, rétablit sans peine tout ce qu'un agent funeste a brisé, ou faussé, ou souillé ou déplacé. Il y a plus : regardez de près, et déjà vous reconnaîtrez une main réparatrice. Quelques poutres

dans la langue adoptive, comme il se fût exprimé lui-même s'il eût écrit dans cette langue. Les autres pensent que ce n'est pas assez; ils veulent retrouver dans la traduction, non-seulement le caractere de l'écrivain original, mais le génie de sa langue [...]» (Marmontel 2020[1777: 4.952]). 
sont étayées ; on a pratiqué des routes au milieu des décombres ; et, dans la confusion générale, une foule $\mathrm{d}^{\prime}$ analogues ont déjà repris leur place et se touchent.

Il y a donc deux intentions visibles au lieu d'une, c'est-à-dire l'ordre et la restauration : mais en nous bornant à la première idée, le désordre supposant nécessairement l'ordre, celui qui argumente du désordre contre l'existence de Dieu la suppose pour la combattre. (OC 4, Soirées: 102-3)

Un orden invisible, que remite al origen, se revela a través de un desorden visible. Una mirada atenta de la naturaleza permite percibir una «main réparatrice». La función del ojo es pues reconocer «des routes au milieu des décombres», que son como «une foule d'analogues». Esta dialéctica entre orden y desorden para De Maistre opera tanto en la naturaleza como en las lenguas: son órdenes paralelos, en la medida en que en el aparente caos de ambos es posible leer la historia de la degradación humana, es decir, las consecuencias del pecado original. Los accidentes de las lenguas se inscriben en una historia interpretada en términos sagrados, así como los descubrimientos paleontológicos pueden ser inscriptos en el relato sobre el Diluvio Universal (OC 10, Carta al conde de Vargas del 20 de octubre [1 de noviembre] de 1807: 498-506), como en general hace la apologética anti-ilustrada (Seguin 2001). La letra de las lenguas traducidas, como los objetos heterogéneos y quebrados de este «vaste cabinet d'histoire naturelle» también debería reconducir a la verdad. Para precisar un poco más la relación entre letra traducida y verdad que propone De Maistre analicemos el «Préface» a su traducción editada en 1816, titulada Sur les délais de la justice divine, del diálogo de Plutarco conocido como De his qui sero a numine puniuntur. Permítaseme una larga cita de este prefacio que nunca ha sido abordado por la crítica:

Animé par l'espoir d'être utile, j'ai entrepris de le [el texto de Plutarco] faire connaître davantage ; et pour y parvenir j'ai pris quelques libertés dont j'espère que Plutarque n'aura point à se plaindre. J'ai fait disparaître la forme du Dialogue, qui marque peu dans ce Traité et qui me gênait en pure perte; car je ne vois pas que celle forme, quelquefois trèsavantageuse, produise ici aucune espèce de beauté ou de mérite réel. Si d'ailleurs le préambule de l'ouvrage n'a pas disparu, comme tout le monde le croyait, jusqu'à M. Wittenbach, qui a jeté sur ce point quelques doutes fondés, Plutarque au moins commence d'une manière abrupte qui ne saurait avoir de grâce pour nous, supposé qu'elle en ait eu pour ses contemporains. J'ai donc tâché de donner un portail à ce bel édifice et d'entrer en matière d'une manière naturelle, en me tenant toujours aussi près de l'auteur qu'il m'a été possible. Lorsque, dans le courant de l'ouvrage, sa pensée me a paru incomplète, j'ai cru pouvoir la terminer, et quelquefois aussi la fortifier par de nouveaux aperçus que je dois à mes propres réflexions ou à la lecture de Platon, auteur que j'aime et pratique volontiers, comme disait Montaigne en parlant d'un tout autre écrivain. S'il m'arrive de rencontrer sur ma route de ces pensées qui ne sont pour ainsi dire qu'en puissance, je les développe soigneusement. Ce sont des boutons que je fais éclore ; je n'ajoute aucune feuille, mais je les montre toutes. J'honore beaucoup les traducteurs qui m'ont précédé. Amyot surtout a bien mérité de la langue française, et son vieux style encore a des grâces nouvelles. Cependant il faut convenir que sa jeunesse surannée n'est guère aimée que des gens de lettres 
extrêmement familiarisés avec son langage. [...] A mesure d'ailleurs qu'on s'élève dans l'antiquité, on trouve plus d'énigmes dans les langues. Le grec, sans remonter plus haut, prouve seul la vérité de cette observation. Cette langue est pleine d'ellipses et d'idiotismes singuliers qui ne se laissent pas aisément saisir. Dans les matières philosophiques, la phrase admet souvent je ne sais quel vague qui ne cède qu'à l'étude obstinée et à la comparaison de différents passages qui s'expliquent les uns par les autres : d'ailleurs chaque peuple a sa langue philosophique, qu'il n'est pas du tout aisé de traduire dans une autre. Celui qui a lu Aristote et Platon, en latin, dans une version littérale de la meilleure main, n'a pas lu réellement ces philosophes. La traduction lui présente souvent les mêmes difficultés que le texte. Celui même qui a bien saisi le sens dans l'original cherche encore longtemps dans sa langue des expressions et des tournures qui rendent bien à son gré ce qu'il a compris, et lorsqu'il les a trouvées c'est une découverte pour lui-même. Il m'a donc paru qu'il était possible à un effort d'attention et d'étude, de faire mieux comprendre, c'est-à-dire mieux goûter Plutarque : mais comme il était essentiel de ne point m'exposer à lui faire tort en mêlant mes pensées aux siennes, voici la méthode que je me suis prescrite. D'abord j'ai suivi exactement l'ordre des chapitres tels qu'on les trouve dans la traduction d'Amyot ; en sorte que la comparaison ne présentera jamais aucune difficulté. Pour éviter même au lecteur qui veut savoir ce qui appartient à chacun, la peine d'une vérification continuelle, j'ai eu soin d'enfermer entre deux astérisques tout ce qui n'est point de Plutarque, et lorsque j'ai trouvé l'occasion (que j'ai toujours cherchée) d'insérer dans ces morceaux étrangers quelques phrases de l'auteur principal, je les ai écrites en lettres italiques : ainsi tout lecteur est mis à même de se reconnaître à chaque ligne, et il peut être sûr d'ailleurs que je n'ai pas été moins soigneux de ne lui dérober rien de ce qui appartient à l'auteur principal. Excepté deux ou trois chapitres extrêmement courts, nullement essentiels et dont la substance même a été conservée, et quelques passages encore absolument étrangers à nos idées, je ne me suis pas permis de supprimer une ligne de Plutarque. Enfin j'ai accompagné mon Ouvrage de quelques notes que j'ai crues utiles sous différents rapports et que j'ai rejetées en grande partie à la fin de l'Ouvrage, pour ne point trop embarrasser les pages. L'œuvre originale aura-t-elle gagné quelque chose à la forme et aux additions qu'elle tient de moi ? Je l'espère, ou plutôt je le désire. (OC 5, Sur les délais...: 370-4)

Lo primero que salta a la vista es la necesidad de tomarse ciertas «libertades» con el texto extranjero: escribirle una introducción más «natural», eliminar la forma diálogo, agregarle todo tipo de citas, comentarios y notas. Este carácter hipertextual de la traducción maistriana convive, paradójicamente, con una reflexión sobre, como diría Cassin (2016), los intraducibles filosóficos: «chaque peuple a sa langue philosophique, qu'il n'est pas du tout aisé de traduire dans une autre». Coherentemente, la lengua griega se presenta «pleine d'ellipses et d'idiotismes singuliers qui ne se laissent pas aisément saisir». Este enigma de la intraductibilidad, sugiere De Maistre, se vuelve más acusado a medida que nos remontamos en la antigüedad hacia la primera lengua. Hipertextualidad e intraductibilidad: es como si De Maistre llenara de comentarios la distancia (para el absolutamente insalvable, dado que no cree en una gramática universal como la de Port-Royal) que existe entre el griego y el francés. Frente a la intraductibilidad de la letra filosófica griega, entonces, un expansivo comentario en francés que incorpora citas del propio Plutarco y pensamientos del traductor. 
Esta reflexión sobre la traducción se hace desde una lengua alejada tanto de la lengua divina como del origen a la vez espontáneo y orgánico que De Maistre supone es el punto de inicio de cada lengua histórica. Más todavía, podría pensarse que esta reflexión sobre la relación entre el francés y las lenguas extranjeras cumple con dos condiciones que para De Maistre son signo de «esterilidad»y «decadencia»: el exceso conceptual y la apertura indiscriminada hacia los intercambios con otras lenguas. Características ambas que por, lo demás, se advierten en la reflexividad que implica la retraducción (Chevrel 2010: 11-20), fenómeno recurrente en la textualidad maistriana. En este prefacio, De Maistre pone en diálogo a su propia traducción con las de la edición y traducción latina de Daniel Wittenbach y con la canónica traducción al francés de Jacques Amyot. De Maistre actúa aquí (como en tantos otros lugares de sus escritos) como relector de otras traducciones de obras, frases o vocablos extranjeros. Para De Maistre traducir es reflexionar sobre la traducción, lo cual significa comparar traducciones y medir la distancia entre las lenguas. No deja de ser paradójico que esta meditación sobre la lengua original, única, genere textos híbridos y plurilingües, es decir que disemine la diferencia entre las lenguas.

Ahora bien: el problema de De Maistre no es tanto hacer una traducción «fiel» del texto de Plutarco, ya sea en términos de literalidad o de sentido, como extraer de ese proceso de traducción y comentario un contenido de verdad:

S'il m'arrive de rencontrer sur ma route de ces pensées qui ne sont pour ainsi dire qu'en puissance, je les développe soigneusement. Ce sont des boutons que je fais éclore. (OC 5 , Sur les délais...: 371)

En la distancia insalvable entre ese francés sospechoso, afectado por el artificio del siglo XVIII, y una lengua más cercana al origen, debe surgir la «verdad», entretejida en un comentario al que nutren «mes propres réflexions» $\mathrm{O}$ «la lecture de Platon». La traducción cobra sentido a partir del reenvío a una verdad filosófica que debe coincidir, en última instancia, con la Palabra (no olvidemos que De Maistre considera a Platón un precursor de la revelación cristiana, Pranchère en De Maistre 2007: 1251-1252). La traducción no intenta traer la letra del texto traducido al francés, como propondrá Chateaubriand más tarde en su traducción de Milton (por lo demás, este énfasis en la literalidad de la traducción podía parecerle a De Maistre demasiado cercano a la sola scriptura protestante). Tampoco el texto traducido se plantea como un producto autónomo en la lengua de llegada. Más bien tiene un carácter que el teórico de la traducción Venuti (2019) llamaría «instrumental», en el sentido de que se subordina toda la operación de traducción a una verdad previa, en este caso la verdad de una tercera lengua, la lengua original en la que resonaría la Palabra. El resultado del sometimiento de la operación de traducción a este instrumentalismo de inspiración teológica es, sin embargo, altamente problemático. La traducción intenta desandar el camino que va del francés al griego, y del griego a la verdad 
de la Palabra, pero a la vez muestra la imposibilidad de ese movimiento, dado que tanto la traducción como el comentario sobre la traducción se hacen, precisamente, en francés. El resultado en términos textuales de esta estructura de reenvíos (del francés traductor a la lengua traducida, y de esta lengua traducida a la Palabra) es una textualidad abigarrada, en la cual se yuxtaponen reescrituras, comentarios y citas en lenguas clásicas. Así se advierte en esta traducción de Plutarco, o en las Soirées.

Este instrumentalismo teológico, entonces, le niega a la traducción el valor de un texto autónomo en la lengua de llegada. En esa lógica se inscribe el rechazo de De Maistre, expresado en De l'Église gallicane (1821) a las traducciones de PortRoyal, particularmente a la traducción del Nuevo Testamento, el llamado «Testamento de Mons», preparado por Louis Isaac le Maître de Sacy, Antoine Arnauld y Pierre Nicole, entre otros eruditos. Las traducciones de Port-Royal proponen un texto en «buen francés» que prescinden del reenvío a la lengua traducida (el hebreo, el griego, el latín): suponen una confianza en la capacidad del francés de decir la verdad que a De Maistre, tal como hemos visto, le parece altamente cuestionable. La traducción legible sería una adulteración, en la medida en que reemplaza el reenvío al texto sagrado original por una suerte de copia degradada. Peor aún, la legibilidad de las traducciones de Port-Royal, que asegura que cualquiera puede leer la Biblia, expresa un espíritu de «démocratie religieuse» (OC 3, De l'Église...: 41). Frente a ese panorama, en De l'Église gallicane De Maistre propone como modelo una visión idealizada de la pedagogía humanista jesuita, en la que juegan un rol fundamental las ediciones comentadas en lengua original o bilingües, tales como la de Virgilio preparada por Charles De La Rue. Estas ediciones, por un lado, exigen el trabajo con la letra original; pero, por otro lado, al editar el texto original, al rodearlo de comentarios, incluso al censurarlo como una «bebida a la que se desinfecta», para limpiarlo de la corrupción del paganismo (OC 3, De l'Église...: 50), evitan que este trabajo con la letra se desvíe de la verdad dogmática.

Pero los textos de De Maistre poco tienen que ver con el orden monológico que suponen estas «ediciones corregidas» (OC 3, De l'Église...: 50) por los eruditos comprometidos con la verdad de la fe católica. El francés de De Maistre se parece más bien al desorden de ese «vasto gabinete». Y ese desorden converge con la forma conversacional (Glaudes 1997: 95-141). En términos teológicos De Maistre prefiere la Palabra antes que la Escritura y en términos de comunicación filosófica prefiere la enseñanza esotérica antes que el tratado exotérico y comprensible para cualquier público. ${ }^{10}$ Esta impugnación de la escritura se expresa en términos textuales en la ficcionalización de intervenciones de la voz humana: género epistolar (que De Maistre piensa como una prolongación de la conversación), plegaria, o diálogo como en las Soirées. El estilo paradojal de De Maistre, los epigramas chocantes dichos «à brûle-pourpoint» (OC 4, Soirées: 177) se acomodan

\footnotetext{
${ }^{10}$ Sobre este punto, $c f r$. por ejemplo la cita a la Carta VI de Platón en Sverdloff (2019: 233-4).
} 
a este tono de conversación de salón, con sus saltos, anacolutos y traits d'esprit. En ese registro de lo oral confluye la desconfianza teológica hacia la letra escrita con el tono mundano del causeur. En las Soirées, el desorden del gabinete natural coincide con el desorden de la conversación, en una escena dialógica que, por lo demás, se inscribe en un idealizado cosmopolitismo (Glaudes 1997: 104-8). En esa lógica de lo discontinuo deben pensarse, por ejemplo, las fantasiosas teorías lingüísticas enunciadas en el segundo entretien. Porque si desde un punto de vista filológico las hipótesis de De Maistre carecen de todo sustento, desde el punto de vista de la lógica asociativa de la conversación estas reflexiones son sumamente evocativas, y parecen formar parte de esa «foule d'analogues» que pueblan, según el saboyano, ese gabinete de historia natural sacudido por un terremoto. Así sucede, por ejemplo, con la difundida pero errónea etimología de «cadaver», que De Maistre cita para ejemplificar la ley de formación de palabras del latín (OC, Soirées: 91). Es falso que CADAVER venga de «CAro DAta VERmibus» (carne dada a los gusanos), pero esta imagen, puesta en el contexto del segundo entretien que trata sobre la relación entre lenguaje y violencia, es sumamente sugerente. El lector se ve convocado a ejercitar su pasión analógica.

La oralidad de las Soirées acompaña esta lengua paradojal, sincopada, hecha de fórmulas sorprendentes, marcándola aún más con lo inconcluso (una inconclusión conversacional que debe contextualizarse, por lo demás, en otra forma de inconclusión, la de la historia editorial de los textos maistrianos, hecha de cartas, pequeños tratados, textos publicados para una circulación restringida, muchos de los cuales fueron conocidos de manera póstuma). Es pues a partir de este francés «molido» desde el cual De Maistre plantea sus propias reescrituras de textos y reflexiona sobre la traducción y las lenguas. Lejos de la idea de «obra concluida» o de forma cerrada que podría asociarse al imaginario de la clarté, este reenvío a la voz y a la Palabra da como resultado textual una serie de fragmentos plurilingües. Una escritura, pues, que en nada se parece al anhelado monolingüismo, sino más bien a esa confusio linguarum que De Maistre le atribuye a la revolución. El cuestionamiento a la lengua francesa de los philosophes del siglo XVIII no termina en un retorno a un estilo oratorio como el de Bossuet, o racionalista como el de Malebranche, tan admirados por De Maistre. Se trata de una diferencia fundamental con Bonald, un reaccionario verdaderamente sistemático. No deja de ser paradójico que la lengua maistriana tenga características que De Maistre les atribuiría a las lenguas degradadas. Leamos en esa clave esta descripción de lenguas de salvajes, en la cual se habla de «débris», «derniers restes», «ruinae»:

Par une suite de la même erreur on a pris les langues de ces sauvages pour des langues commencées, tandis qu'elles sont et ne peuvent être que des débris de langues antiques ruinées [...] dégradées comme les hommes qui les parlent. (OC 4, Soirées: 63)

Si nous avions [...] seulement les dictionnaires de ces langues, je ne doute pas que nous n'y trouvassions de ces mots dont je vous parlais il n'y a qu'un instant, restes évidents d'une 
langue antérieure parlée par un peuple éclairé. Et quand même nous ne les trouverions pas, il en résulterait seulement que la dégradation est arrivée au point d'effacer ces derniers restes : Etiam periere ruinae. Mais dans l'état quelconque où elles se trouvent, ces langues ainsi ruinées demeurent comme des monuments terribles de la justice divine. (OC 4, Soirées, 106-7)

Y vayamos ahora al reverso de la corrupción de los pueblos salvajes, la esterilidad de las lenguas sofisticadas, en donde se verifica tanto el triunfo del razonamiento como la invasión de palabras extranjeras. En el segundo entretien, el Conde le dice al senador ruso:

contemplez votre nation, et demandez-lui de quels mots elle a enrichi sa langue depuis la grande ère ? Hélas! cette nation a fait comme les autres. Depuis qu'elle s'est mêlée de raisonner, elle a emprunté des mots et n'en a plus créé. Aucun peuple ne peut échapper à la loi générale. Partout l'époque de la civilisation et de la philosophie est dans ce genre, celui de la stérilité. (OC 4, Soirées: 94)

Una lengua pues de «débris», de palabras prestadas, que recuerda a los «décombres» del gabinete de historia natural después de un terremoto: no habría mejor descripción de la lengua maistriana. Una lengua de reescrituras, citas, fragmentos, traducciones, inserciones de otras lenguas. $Y$ una lengua que participa, a su modo de ese carácter excesivamente abstracto y filosófico, asociado con la esterilidad, que para De Maistre define al siglo XVIII. Así se advierte, por ejemplo, en el par conceptual «vouer/dévouer» o en el neologismo filosófico «réité», términos que encontramos en en L'éclaircissement sur les sacrifices (1821): se trata de verdaderos intraducibles filosóficos (Cassin 2016: 27-86) cuya creación implica a la vez un sofisticado trabajo con la lengua francesa y una tupida red de relaciones con las lenguas clásicas y modernas (Sverdloff 2019: 194-6). En el mismo sentido, lejos de la unidad orgánica que De Maistre reclama para las lenguas en sus orígenes, los neologismos «sans-culottisme» (OC 8, Réflexions sur le protestantisme: 97), «riénisme» (OC 13, Carta al cardenal Severoli de 1816: 476) o «théophobie» (OC 4, Soirées: 282) intentan describir la aceleración de esta nueva temporalidad en la cual la experiencia ya no coincide con el horizonte previo de expectativas (Koselleck 1993: 42-66)

Este carácter inconcluso sitúa a la escritura maistriana en el territorio del ensayo y la diferencia claramente de la sistematicidad de la apologética contrarrevolucionaria más dogmática. Y la errancia del ensayo (que como se sabe, es el género de la exploración de la empiria) permite el deslizamiento entre la censura teológica de Babel y la fascinación por la pluralidad de lenguas. El gabinete de historia natural deviene gabinete de curiosidades, es decir un espacio en el cual la materialidad de los objetos heterogéneos, ${ }^{11}$ en este caso las lenguas, fascina a la mirada y desbarata a la filosofía previa. A veces el logócrata (Steiner 2006: 5-17) le cede espacio al curioso y surge un interés puramente gratuito por

11 Para una aproximación a la historia del gabinete de curiosidades cfr. Gabrieloni 2018. 
las lenguas, por la traducción de un término, una grafía, un proverbio extranjero. Esta tensión entre negación y afirmación de Babel es constitutiva de la lengua maistriana. Se trata de una escritura que solo puede plantearse el reenvío a la Palabra desde la superficie plurilingüe de una lengua «molida», que al reflexionar sobre la unidad esparce los fragmentos, que al pensar en la Palabra original disemina el comentario y la diferencia entre las lenguas. Una escritura que, al rechazar la violencia revolucionaria, produce una nueva violencia sobre la lengua, a la que convierte en ruinae, en décombres, en débris.

\section{CONCLUSIONES: TRADUCCIÓN Y PARADOJA}

La teoría y la práctica de la traducción de De Maistre resultan, como no podía ser de otro modo, sumamente paradojales. Por un lado, tenemos la condena teológica contra Babel, a la que el saboyano asocia con el pecado original. Por el otro, sin embargo, advertimos que la llegada de Pentecostés se enmarca en una «verdadera era de la traducción»: para suprimir Babel se deben intensificar las operaciones traducción, es decir, se debe acelerar Babel. Este estatuto paradójico se advierte también en la materialidad de los textos. Para De Maistre escribir (incluso con el objeto de impugnar Babel) supone siempre hibridar comentario y traducción de forma indiscernible, tal como puede observarse en sus obras publicadas y en sus cuadernos de anotaciones. Este movimiento contradictorio debe inscribirse en la general duplicidad de De Maistre en relación a la palabra escrita: este erudito polemista, que también supo ser un bibliófilo, nunca cesó de lanzar invectivas contra la escritura y el libro. La práctica de este fustigador de la pluralidad de lenguas, que pensaba a la confusio linguarum como un mal teológico-político, tiene amplias zonas de convergencia con la «Ilustración cosmopolita». A la luz de esta constatación, no deja de ser irónico que De Maistre se convirtiera en el siglo XX en una referencia central de tantas derechas xenófobas europeas y latinoamericanas.

De Maistre tiene en muy poco estima a la lengua de su época: la verdad no puede manifestarse en el francés del siglo XVIII y de la revolución. Es por eso que cada traducción al francés debe reenviar al texto original. De allí el valor que le atribuye a la pedagogía humanista clásica, cuyo modelo es la educación jesuítica que el mismo recibió, en la medida en que supone un constante trabajo con el texto original. La traducción debe señalar o rodear al texto extranjero, pero en ningún caso debe sustituirlo, particularmente en el caso del texto sagrado. En esa línea se inscriben los ataques a las traducciones de Port-Royal: esas traducciones que adaptan el texto evangélico al genio del francés acercan (y adulteran) lo que debería permanecer lejano: son formas de la «democracia religiosa». Estamos ante una visión reaccionaria y decadentista de las lenguas, fundada en una perspectiva teológica, evidentemente anacrónica. Y sin embargo esta perspectiva anacrónica termina provocando un radical descentramiento del modelo de la clarté y de las belles infidèles. Un descentramiento que abre la lengua a la violencia 
revolucionaria y que sacude las normas de la retórica clásica. ${ }^{12}$ Esta combinación entre teología y violencia del lenguaje también se advierte en el uso de la alegoría (Sverdloff 2019: 111): la vuelta a este venerable modo de representación, teorizado por Orígenes y otros autores cristianos, le sirve sin embargo a De Maistre para representar la aceleración del acontecimiento revolucionario. ${ }^{13}$

Entonces: la lengua maistriana abandona la seguridad de la clarté como valor estilístico para abrirse a la «verdad», entendiéndose por tal ese rastro que la Palabra habría dejado en otras lenguas, quizá menos degradadas que el francés del siglo XVIII. Tal como hemos visto, este reenvío a la verdad supone una práctica de escritura y traducción que acoge la discontinuidad de lo extranjero. La pregunta por el original no hace más que esparcir las traducciones, los comentarios, las reescrituras, las citas: disemina la pluralidad, la diferencia de las lenguas. Así como el rechazo de la violencia revolucionaria provoca otra violencia en la lengua, la necesidad de una lengua única solo puede ser expresada esparciendo los fragmentos, para peor en una lengua «degradada» como el francés del siglo XVIII. El francés queda en una especie de estado de inconclusión, «molido»y «mezclado», como los hombres de la época revolucionaria. Estas paradojas definen la singularidad de De Maistre y alejan su escritura de la de otros reaccionarios, a la vez que lo acercan al lugar excéntrico de un autor como Sade, quien también acudía a la paradoja para representar la violencia de la revolución.

Digamos para finalizar que las paradojas maistrianas en torno a la traducción evocan temas a los que se refiere Walter Benjamin en Die Aufgabe des Übersetzers (1921): Babel, la degradación de las lenguas históricas, el retorno a la lengua original, la oralidad divina, la relación entre traducción y teología, la adecuación cratílica entre significado y significante, la lectura interlineal del texto sagrado, la relación entre traducción profana y traducción religiosa, la reflexión sobre el fragmento que debe conducir a la verdad (Berman 2015). Las conexiones entre De Maistre y Benjamin ya han sido abordadas por la crítica (Kageura 2011), pero hasta ahora ningún trabajo las ha estudiado específicamente desde el ángulo de la teoría de la traducción: sobre ellas discutiré en otro artículo, de próxima aparición.

\footnotetext{
12 Sobre la crisis de la retórica y su relación con la revolución, cfr. Delon 1999.

13 «Si l'on s'arrête en particulier sur les actes de la Convention nationale, il est difficile de rendre ce qu'on éprouve. Lorsque j'assiste par la pensée à l'époque de son rassemblement, je me sens transporté, comme le Barde sublime de l'Angleterre, dans un monde intellectuel; je vois l'ennemi du genre humain séant au manège et convoquant tous les esprits mauvais dans ce nouveau Pandxmonium; [...] je vois tous les vices de la France accourir à l'appel, et je ne sais si j'écris une allégorie» (OC 1, Considérations sur la France: 52-3).
} 


\section{BIBLIOGRAFÍA}

AA.VV. (2011), Enlightenment Cosmopolitanism, Adam, D. y Tihanov, G. (eds.), New York, Legenda-Modern Humanities Research Association and Routledge.

AA.VV. (2005), Joseph de Maistre. Dossier H, Barthelet, P. (ed.), Lausanne, L'âge de l'homme.

AA.VV. (2001), Joseph de Maistre's Life, Thought, and Influence. Selected Studies, Lebrun, R. A. (ed.), Montreal \& Kingston-London-Ithaca, McGill-Queen's University Press.

France Archives. Portail National des Archives. Archivos de la familia De Maistre [en línea]. Chambéry: Conseil général de la Savoie. Archives départementales, 24/04/2014 [Consulta: 13/09/2020]. Disponible en: <https://francearchives.fr /findingaid/91d305859357f01a34d8b5c3de72457a6dab99c5>.

Armenteros, C. (2011), The French Idea of History: Joseph de Maistre and his Heirs, 1794-1854, Ithaca-Londres, Cornell University Press.

Auroux, S., KOERnER, E. F. K., NiedereHE, H.-J. y VerSTEEGH, K. (eds.) (2000-2), History of the Language Sciences. Geschichte der Sprachwissenschaften. Histoire des sciences $d u$ langage. An International Handbook on the Evolution of the Study of Language from the Beginnings to the Present. Ein internationales Handbuch zur Entwicklung der Sprachforschung von den Anfängen bis zur Gegenwart. Manuel international sur l'évolution de l'étude du langage des origines à nos jours, vol. 1 y 2., Berlin-New York, Walter de Gruyter.

BAlibar, R. y LAPORTE, D. (1974), Le français national. Politique et pratiques de la langue nationale sous la Révolution française, Paris, Librairie Hachette.

BenJAmiN, W. (1991), Gesammelte Schriften, tomo V.1-2, Das Passagen-Werk, Frankfurt am Main, Suhrkamp Verlag.

BERLIN, I. (2004), «Maistre», en La traición de la libertad: Seis enemigos de la libertad humana, Hardy, E. (ed.) México, FCE, 121-140. (trad. de Bigorra, M. A. N., Freedom and Its Betrayal. Six Enemies of Human Liberty, Princeton, Princeton University Press, 2002).

BERMAN, A. (2015), La era de la traducción. "La tarea del traductor" de Walter Benjamin, un comentario, Buenos Aires, Dedalus editores. (trad. de López Arriazu, E., L'Âge de la traduction. "La tâche du traducteur" de Walter Bnejamin, un commentaire, Paris, PUV Éditions, 2008).

BERMAN, A. (2011), L'épreuve de l'étranger : Culture et traduction dans l'Allemagne romantique, Paris, Gallimard.

CAssin, B. (2016), Éloge de la traduction. Compliquer l'universel, Paris, Fayard.

Chevrel, Y. (2010), «Introduction : la retraduction - und kein Ende», en La Retraduction, Kahn, R. y Seth, C. (eds.), Rouen, Publications des Universités de Rouen et Du Havre, 11-20.

Chevrel, Y., CoIntre, A. Y Tran-Gervat, Y.-M. (2014), «Bilan», en Histoire des traductions en langue française. XVI e et XVIII siècles, Chevrel, Y., Cointre, A. y TranGervat, Y.-M (dirs.), Paris, Verdier, 1283-1297. 
CheVReL, Y., D'HULST, L. Y LOMBEZ, C. (2012), «Introduction», en Histoire des traductions en langue française. XIXe siècle, Chevrel, Y., D’hulst, L. y Lombez, C. (dirs.), Paris, Verdier, 31-50.

CIORAN, E. (2011[1977]), «Essar sur la pensée réactionnaire», en CEuvres, Paris, Gallimard, col. Bibliothèque de la Pléiade, 1131-1173.

Compagnon, A. (2016), Les antimodernes. De Joseph de Maistre à Roland Barthes, París, Gallimard.

De Lubac, H. (1989), La posteridad espiritual de Joaquín de Fiore. I. De Joaquín a Schelling, Madrid, Encuentro ediciones. (trad. de Martín de Ximeno, J. H., La postérité spirituelle de Joachim de Flore, Éditions Lethielleux, Paris, 1981).

De MAistre, J. (2007), CEuvres, Glaudes, P. de, Paris, Robert Laffont.

DE MAISTRE, J. (1884), CEuvres complètes, 14 vols, Lyon, Librairie générale catholique Vitte et Perrusse.

De Rivarol, A. (1797[1784]), De l'universalité de la langue française, Paris, Cocheris.

DELON, M. (1999), «Procès de la rhétorique, triomphe de l'éloquence (1775-1800)», en Histoire de la rhétorique dans l'Europe moderne, Fumaroli, M. (ed.), Paris, Presses Universitaires de France, 1001-1017.

DERRIDA, J. (1967), De la grammatologie, Paris, Les Éditions de Minuit.

DiDEROT, D. (1772[1751]), «Lettre sur les Sourds \& les Muets, à l'usage de ceux qui n'entendent \& qui parlent», en CEuvres philosophiques et dramatiques, s/editor, T.2. Amsterdam, s/d editorial, 2-123.

ECO, U. (1998), Serendipities : language and lunacy, New York, Columbia University Press, (trad. de Weaver, W., «La linguistica anti-illuministica di Joseph de Maistre», en Studi orientali e linguistici V, Miscelánea en memoria de Luigi Rosiello, 1995-6).

Froidefont, M. (2010), Théologie de Joseph de Maistre, Paris, Éditions classiques Garnier. GABRIELONI, A. L. (2018), «Literatura e historia (natural) del arte», Saga, 9, 35-56.

GARRARD, G. (2006), Counter-Enlightenments. From the eighteenth century to the present, New York, Routledge.

GLAUDES, P. (2000), «Joseph de Maistre essayiste», Cahiers de l'Association internationale des études francaises, 52, 117-132.

GLAUDES, P. (1997), Joseph de Maistre et les figures de l'histoire : trois essais sur un précurseur du romantisme français, Clermont-Ferrand, Université Blaise-Pascal.

KAGEURA, R. (2011), «Maistrian themes in Walter Benjamin's sociology», en Joseph de Maistre and his European Readers: From Friedrich von Gentz to Isaiah Berlin, Armenteros, C. y Lebrun, R. A. (eds.), Leiden, Brill, 151-170.

KOSELleCK, R. (1992), Futuro pasado. Para una semántica de los tiempos históricos, Barcelona, Paidós. (trad. de Smilg, N., Vergangene Zukunft. Zur Semantik geschichtlicher Zeiten, Frankfurt am Main, Suhrkamp Verlag, 1979).

LABARTHE, P. (2015[1999]), Baudelaire et la tradition de l'allégorie, pref. de Yves Bonnefoy, Droz, Genève.

MARMONTEL, J.-F. (1777), «Traduction», en Supplément à l'Encyclopédie, ou dictionnaire raisonné des sciences, des arts et des métiers, par une société de gens de lettres, vol. 4, 
Amsterdam, Rey Libraire, M. (ed.), 952-954. Disponible en <https://artflsr v03.uchicago.edu/philologic4/supplement/navigate/4/1413/>.

MARCUSE, H. (2005), «L'autorité (une théorie antirationaliste de la domination des masses)», en Joseph de Maistre. Dossier H, Barthelet, P. (ed.), Lausanne, L'âge de l'homme, 358-359. (trad. de Heim, C. y Horkheimer, M., Studien über Autorität und Familie, Schriften des Instituts für Sozialforschung 5, 1936).

Philippe, G. (2010), Le français, dernière des langues. Histoire d'un procès littéraire, Paris, Presses Universitaires de France.

PRANCHÈRE, J.-Y. (2004), L'autorité contre les lumières : la philosophie de Joseph de Maistre. Genève, Droz.

SEGUIN, M. S. (2001), Science et religion dans la pensée française du XVIII ${ }^{E}$ siècle: le mythe du Déluge universal, Paris, Honoré Champion.

STEINER, G. (2006), Los logócratas, Madrid, Siruela. (trad. de Cóndor, M., « Logocrats (a note on de Maistre, Heidegger and Pierre Boutang ", en Langage et Politique, Cranston, M. y Mair, P. (eds.), Bruxelles, Bruylant, 1982).

STERNHELL, Z. (2010[2006]), Les anti-Lumières. Une tradition du XVIII siècle à la guerre froide, Paris, Gallimard.

SVERDLOFF, M. (2019), «Elucidación sobre los sacrificios, de Joseph de Maistre», Stylos, 28, 106-282.

THURSTON, B. (2005), «Joseph de Maistre et la Tour de Babel», en Joseph de Maistre. Dossier H, Barthelet, P. (ed.), Lausanne, Éditions de l'âge de l'homme, 309-313.

THURSTON, B. (2001), «Joseph de Maistre's Theory of Language: Language and Revolution», en Joseph de Maistre's Life, Thought, and Influence. Selected Studies, Lebrun, R. A. (ed.), Montreal \& Kingston-London-Ithaca, McGill-Queen's University Press, 105-119.

THURSTON, B. (2010), «Joseph de Maistre: the paradox of the writer», en The New enfant du siècle: Joseph de Maistre as a Writer, Armenteros, C. y Lebrun R. A. (eds.), St. Andrews, Centre for French History and Culture of the University of St. Andrews, 75-98.

VenutI, L. (2019), Contra Instrumentalism: A Translation Polemic, Lincoln, University of Nebraska Press. 